\title{
Rising sea levels: Will we adapt or drown?
}

Written by: Lisa Danielson, OECD Environment Directorate and Michael Mullan, OECD Environment Directorate

Last update: 18 June 2018

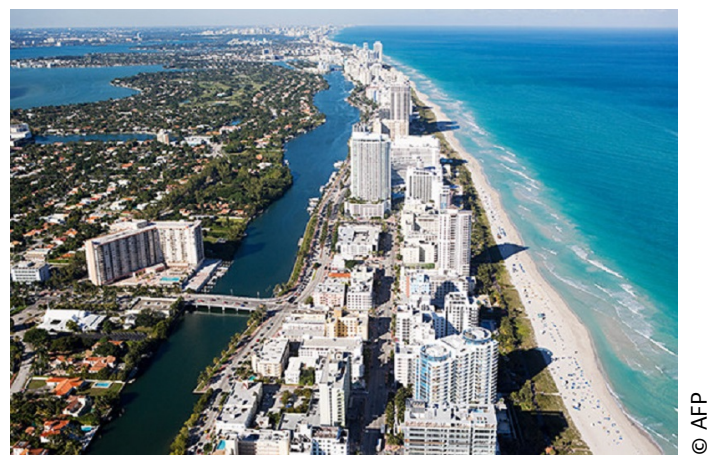

Low-lying island states like the Maldives and densely populated coastal cities like New York have at least one thing in common: they are faced with the challenge of rising sea levels. In fact, close to a quarter of the world's population lives within 100 metres of a coast. Although we cannot predict exactly the pace and upper limits of the current rise, we do know that sea levels will continue rising and that the impacts will be costly.

In Europe alone, there are at least $€ 0.5$ to 1 trillion of assets located within 500 metres of the coast, a 2009 estimate of property values that has almost certainly gone up. Moreover, if the West Antarctic and Greenland ice sheets break up, we will be looking at over two metres of sea-level rise by 2100. That is enough to flood, if not submerge, major cities from Miami to Shanghai, not to mention delta countries such as Bangladesh.

Ultimately, the only way to reduce the risk of unmanageable, catastrophic impacts is for countries to meet the global commitment of keeping temperature rises well below 20C. In addition to this, what else can policymakers do to prevent the worst from happening?

For a start, they need to assess clearly what is at risk if their coastlines are hit. People are clearly the most important, but policy must also be about safeguarding (and possibly relocating) so-called fixed assets too, which our towns and cities, and often whole regions rely on: hospitals, power generators, art and heritage, business and transport equipment, data centres, and much more. And they must 
do more to discourage people from settling and building up new assets in these vulnerable zones in the future.

\section{More implementation needed}

Many countries are developing national and sub-national strategies for adapting to climate change that consider how they will prepare for sea-level rise. For instance, The Netherlands' Delta programme is investing over $€ 1$ billion per year to manage the risk of flooding from the sea and rivers. All OECD countries have strategies that are either ready or under development, including plans for adapting to climate change.

However, time is ticking and it is important to advance on these strategies and assure their implementation sooner rather than later. Just look around: in poorer countries and in some rich ones too, we are still building in high-risk areas, and many infrastructures being developed are simply not sustainable or able to resist rising sea levels. And, in some cases, disaster compensation agreements continue to use national funds to rebuild destroyed areas exactly as they were before, with no adaptation schemes and, so it would seem, no lessons learned.

In the poorest and most vulnerable regions, climate resilience and adaptation plans are impeded by inadequate institutional capacity, human resources and financing. They are further hampered by rampant, unplanned urbanisation, with informal settlements typically located in the riskiest areas. International financial resources are starting to be mobilised to support adaptation. Vanuatu is revegetating parts of its coast with international support. In Tuvalu, the United Nations Development Programme (UNDP) and the Green Climate Fund are supporting the government's efforts to protect the coast through ecosystem restoration and hard defences, such as sea walls.

But even in wealthy countries, a range of financial and institutional constraints and policy inconsistencies are not only getting in the way of implementation, but paving the way for future disasters . For example, local governments may have limits on how much they can borrow financially, and often receive most of their funding from property taxation. As a result, they

a range of financial and institutional constraints and policy inconsistencies are not only getting in the way of implementation, but paving the way for future disasters may baulk at measures that stop new coastal developments, particularly in highvalue beachfront areas, no matter how vulnerable these coasts may be to erosion and flooding. Real estate markets can be oblivious to flood and erosion risks, with properties in the most precarious places commanding very high prices. For instance, in 2009, a local government in Australia was considering buying properties in a high-risk coastal area in order to protect the assets, but could not afford to do so as the property values were so high. 


\section{Seeing where we are heading}

Better information is important, but so is policy action. Thankfully, pro-active adaptation is starting to happen, and the OECD has developed a framework to support such initiatives, to improve spatial planning, for instance, as well as identify assets and utilities, and build cost-effective resilience mechanisms into infrastructure investment. New York has been adding new green spaces, adapting waste-water treatment plants and reworking hard surfaces on roads and roofs of buildings to allow faster collection and run-off of excess flood water. Other countries, including France and South Africa, have implemented a range of innovative nature-based solutions to coastal risk such as restoring and protecting wetlands that absorb excess water, and coastal erosion-reducing dunes and reefs.

Better monitoring and assessment can also help inform future policy and improve practices. In the UK, the national climate change risk assessment includes an evaluation of people and property at risk of coastal inundation and erosion alongside measures to reduce that risk.

In 2017 the oil city of Houston was flooded after the passing of a major hurricane, with scores of casualties and costly damage to property and other assets. At around the same time, Bangladesh was struck by severe flooding which killed over a thousand people. How bad do things have to get before we begin to take pro-active development decisions to safeguard our coastal communities and homes from rising sea levels? It is not enough to be warned. For as Albert Einstein once said, while a clever person solves a problem, a wise person seeks to prevent it.

\section{References}

National Climate Change Adaptation http://dx.doi.org/10.1787/9789264229679en

Read "Adaptation to Climate Change in the Coastal Zone in Vanuatu" http:// www.pacific.undp.org/content/pacific/en/home/operations/projects/ environment_and_energy/Van_CAP

Holloway, Cas (2011), "Beautiful waterways for the Big Apple”, OECD Observer http://oe.cd/29b

Climate-resilient infrastructure http://dx.doi.org/10.1787/02f74d61-en

Rigg, Kelly (2012), "Waking up to climate change”, OECD Observer. http:// oe.cd/29c

The Economic Consequences of Climate Change http://dx.doi.org/ 10.1787/9789264235410-en 